\title{
Estimativa de parâmetros genéticos para caracteres silviculturais e densidade do lenho em teste de progênies de Eucalyptus urophylla
}

\author{
Genetic parameters estimates for silvicultural traits and \\ wood density in Eucalyptus urophylla progeny test
}

\author{
Eduardo Pinheiro Henriques ${ }^{1}$, Cristiano Bueno de Moraes ${ }^{2}$, Alexandre Magno Sebbenn ${ }^{3}$, \\ Mario Tomazello Filho ${ }^{4}$, Mário Luiz Teixeira de Moraes ${ }^{5}$ e Edson Seizo Mori ${ }^{6}$
}

\section{Resumo}

Nos programas de melhoramento genético de espécies de eucalipto, testes de progênies de polinização aberta são usualmente utilizados na seleção de árvores superiores. Dessa forma, no presente estudo foram estimados parâmetros genéticos em progênies de Eucalyptus urophylla para os caracteres altura total das árvores, diâmetro à altura do peito (DAP), volume do fuste e densidade aparente do lenho aos $1,2,3,5$ e 7 anos de idade. O delineamento experimental utilizado foi o de blocos casualizados com 77 tratamentos, 6 repetições e 6 plantas por parcela linear. O teste da razão de verossimilhança (LRT) revelou diferenças altamente significativas em nível de $1 \%$ de probabilidade $(p<0,01)$ entre os caracteres avaliados, exceto para o DAP e a densidade aparente do lenho no $1^{\circ}$ ano, significativo $(p<0,05)$ e não significativo, respectivamente. O valor dos coeficientes de variação experimental foi no máximo de $9,23 \%$ para altura, 10,66\% para DAP, 29,74\% para volume do tronco e 13,60\% para densidade do lenho, todos na idade de 1 ano, decrescendo com o aumento das idades. A herdabilidade média das progênies $\left(\hat{h}_{m}^{2}\right)$ foi de 0,80 para altura, de 0,67 para DAP, de 0,72 para volume e de 0,83 para densidade do lenho, aos 7 anos, idade usual de colheita. O coeficiente de determinação dos efeitos de parcela $\dot{C}_{p}^{2}$ foi abaixo de $1 \%$ para todos os caracteres nas idades de 2, 3, 5 e 7 anos. A acurácia $r_{a a}$ foi da ordem de $87 \%$ para altura, $78 \%$ para DAP, $83 \%$ para volume e de $90 \%$ para densidade, a partir do segundo ano, para todos os caracteres e idades. Os resultados indicam forte controle genético dos caracteres de crescimento e de qualidade do lenho, com a possibilidade de obtenção de ganhos genéticos no processo de seleção aplicado entre e dentro de progênies.

Palavras-chave: densidade do lenho; densitometria de raios X; parâmetros genéticos; teste de progênie.

\begin{abstract}
In eucalypt species, progeny tests of open pollinated trees are usually used for selecting superior genotypes in genetic improvement programs. In this study, genetic parameters were estimated in a progeny test of Eucalyptus urophylla for the traits total tree height, diameter at breast height (DBH), stem volume and apparent density of the wood at 1, 2, 3, 5 and 7 years of age. The experimental design was randomized blocks with 77 treatments, 6 replicates and plots containing 5 plants in rows. The likelihood ratio test (LRT) revealed highly significant differences at a probability level of $1 \%(p<0.01)$ between the traits assessed, except for DBH and apparent density of the wood at the 1 st year of growth, which were significant $(p<0.05)$ and not significant, respectively. The values of the residual coefficients of variation were $9.23 \%$ for tree height, $10.66 \%$ for $\mathrm{DBH}, 29.74 \%$ for stem volume and $13.60 \%$ for wood density, all of them at the age of 1 year, decreasing according to the increase of age. The progeny mean heritabilities $\left(\hat{h}_{m}^{2}\right)$ were 0.80 for tree
\end{abstract}

${ }^{1}$ Doutor em Engenharia Florestal. UNESP - Universidade Estadual Paulista "Júlio de Mesquita" Filho / Faculdade de Ciências Agronômicas. Caixa Postal 237 - 18.610-237 - Botucatu, SP, Brasil. E-mail: eduardopinheirohenriques@gmail.com 2Professor Adjunto do Departamento de Ciências Florestais. UFT - Universidade Federal do Tocantins - 77404-970 - Gurupi, TO, Brasil. E-mail: cb moraes2004@yahoo.com.br

3Pesquisador Doutor. IF -Instituto Florestal. Caixa Postal 1322 - 01059-970, São Paulo, SP, Brasil. E-mail: alexandresebbenn@yahoo.com.br

${ }^{4}$ Professor Titular do Departamento de Ciências Florestais. USP - Universidade de São Paulo /ESALQ - Escola Superior de Agricultura Luiz de Queiroz. Avenida Páduas Dias, 11 - Caixa Postal 09 - 13418900 - Piracicaba, SP, Brasil. E-mail: mtomazel@usp.br

${ }^{5}$ Professor Titutar do Departamento de Fitotecnia e Tecnologia de Alimentos e Socio Economia.UNESP - Universidade Estadual Paulista "Júlio de Mesquita" Filho / Faculdade de Engenharia de Ilha Solteira. Caixa Postal 31 - 15385-000 - Ilha Solteira, SP, Brasil. E-mail: teixeira@agr.feis.unesp.br

${ }^{6}$ Professor Titulador do Departamento de Produção e Melhoramento Vegetal. UNESP - Universidade Estadual Paulista "Júlio de Mesquita" Filho / Faculdade de Ciências Agronômicas. Caixa Postal 237 - 18.610-237 - Botucatu, SP, Brasil. E-mail: esmori@fca.unesp.br 
height, 0.67 for $\mathrm{DBH}, 0.72$ for stem volume and 0.83 for wood density, at age 7 years, when the rotation cycle is usually completed. The coefficients of determination of the plot effect of $\left(\hat{C}_{p}^{2}\right)$ were below $1 \%$ for all characters at the ages of 2, 3, 5 and 7 years. Accuracies $\left(r_{a x}\right)$ were $87 \%$ for tree height, $78 \%$ for DBH, $83 \%$ for stem volume and $90 \%$ for wood density after the second year of growth for all traits and ages. The results indicate a strong genetic control for the traits associated to the tree growth and wood density, with the possibility of obtaining genetic gains when the selection is performed both within and among progenies.

Keywords: genetic parameters; progeny test; wood density; x-ray densitometry.

\section{INTRODUÇÃO}

A espécie Eucalyptus urophylla foi introduzida no Brasil a partir da década de 1970 por meio de sementes coletadas em árvores de populações naturais ocorrentes nas ilhas orientais do arquipélago de Sonda, na latitude de $7-10^{\circ} \mathrm{S}$ e altitude de 300a $3.000 \mathrm{~m}$ (PRYOR; JOHNSON, 1971). A sua introdução teve como um dos objetivos a substituição das árvores de E. grandis susceptível ao fungo Cryphonectria cubensis, agente causal do cancro do tronco em plantações florestais nas regiões costeiras dos estados do Espírito Santo e da Bahia (ROCHA et al., 2006). Ainda, diversas procedências com diferentes amplitudes genéticas de E. urophylla foram, da mesma forma, introduzidas pela iniciativa de empresas florestais vinculadas à produção de celulose e de carvão vegetal para a siderurgia (FONSECA et al., 1986). E. urophylla apresentou excelente adaptação às diversas regiões edafoclimáticas, inclusive nas áreas de Cerrado, limitantes ao crescimento de E. grandis devido à deficiência hídrica. Assim, a espécie E. urophylla com sua alta taxa de crescimento volumétrico, capacidade de brotação, comprovada rusticidade e potencial de adaptação tem sido utilizada na síntese de híbridos com E. grandis (ROCHA et al., 2006). As plantas híbridas de E. urophylla $x$ E. grandis mostraram-se tolerantes ao agente causal do cancro do tronco e ao déficit hídrico, apresentando, ainda, bom crescimento e madeira de qualidade para a utilização industrial.

Atualmente, os programas de melhoramento genético direcionados para a produção de híbridos interespecíficos de eucaliptos das espécies das Seções Transversaria e Exertaria têm como base E. urophylla para a obtenção de clones de rápido crescimento e com elevada qualidade de madeira (GRATTAPAGLIA, 2007). Nesse sentido, a estratégia para o aumento da eficiência dos programas de melhoramento das espécies de eucalipto está associada à obtenção de híbridos e posterior clonagem com a produção, captura e multiplicação de combinações superiores. Os híbridos de eucaliptos possuem maior plasticidade de adaptação às variações presentes nos sítios florestais, sendo mais produtivos e com melhor característica da madeira (TITON et al., 2003). Em paralelo e com significativo potencial como ferramenta para a aplicação nos programas de melhoramento genético, destacam-se as pesquisas nas áreas de dendrocronologia (anéis de crescimento) (BROOKHOUSE, 2006) e de densitometria de raios X em eucaliptos (KNAPIC et al., 2014;TOMAZELLO FILHO et al., 2008).

O presente trabalho teve como objetivo estimar parâmetros genéticos para caracteres de crescimento (altura, DAP e volume) e densidade aparente do lenho em árvores de um teste de progênies de E. urophylla a diferentes idades, para possibilitar a formação de (i) um Pomar de Recombinação por Polinização Aberta, com a melhor árvore de cada parcela, por repetição, por progênie (total de até seis indivíduos por repetição), (ii) um Pomar de Hibridação por Polinização Controlada, via enxertia, com o melhor indivíduo de cada repetição (total de até um indivíduo por repetição e/ ou 6 por progênie), com o fim de promover a introgressão de genes desejáveis para a produção de híbridos interespecíficos de alta produtividade e qualidades tecnológicas da madeira, para melhor usar a variância genética aditiva $\left(\hat{\sigma}_{a}^{2}\right)$ e (iii) selecionar os dez melhores indivíduos do teste, para clonagem, visando explorar a variância genética total $\left(\hat{\sigma}_{g}^{2}\right)$.

\section{MATERIAL E MÉTODOS}

Caracterização do teste de progênies: o teste de progênies de E. urophylla foi implantado em novembro de 2003 e pertence ao acervo das pesquisas em melhoramento genético da empresa Aperam 
Bioenergia Ltda. Constitui-se de 77 progênies de polinização aberta, obtidas do pomar de sementes clonal - 2000 (Tabela 1), formado a partir de clones de quatro outros pomares. O teste de progênies foi instalado na área denominada Embaúbas (Talhão 575), localizado no município de Itamarandiba - MG (latitude $17^{\circ} 44^{\prime} 45^{\prime \prime} \mathrm{S}$; longitude $42^{\circ} 45^{\prime} 11^{\prime \prime} \mathrm{W}$ e altitude $1.000 \mathrm{~m}$ ). A preparação do terreno consistiu de subsolagem e aplicação concomitante de $500 \mathrm{~kg} / \mathrm{ha}$ de fosfato natural de Araxá em filete contínuo a $20 \mathrm{~cm}$ de profundidade. Foi realizada adubação de plantio de $170 \mathrm{~g} /$ planta de NPK 04-26-16 + 1\% de Zn + 1\% de Cu e aplicação a lanço, de duas toneladas de silicato de Ca e de $\mathrm{Mg}$. Foram feitas mais duas adubações à base de $\mathrm{KCl}+0,7 \%$ de $\mathrm{B}$, nos dois primeiros anos e ainda controle de formigas cortadeiras e da matocompetição.

Tabela 1. Composição do teste de progênies oriundo do pomar de sementes clonal de Eucalyptus urophylla localizados no município de Itamarandiba - MG.

Table 1. Composition of progeny test from the clonal seed orchard of Eucalyptus urophylla located in Itamarandiba - MG.

\begin{tabular}{llll}
\hline Pomares Constituintes & Composição do Pomar & Procedência & Origem \\
Pomar de sementes clonal 1984 & APS - 1981 - 57 matrizes & Timor & Timor \\
\hline & PSC - 1984 - 32 matrizes & Turmalina - MG & Timor \\
Pomar de sementes clonal 1989 & APS - 1981 - 17 matrizes & Timor & Timor \\
& Anhembi - NA-29-15 matrizes & Anhembi - SP & Timor \\
& Anhembi - NA-30 - 8 matrizes & Anhembi - SP & Timor \\
\hline Pomar de sementes clonal 1991 & PSC - 1984 - 90 matrizes & Itamarandiba - MG & Timor \\
\hline Pomar de sementes clonal 1996 & APS - 1985 - 64 matrizes & Timóteo - MG & Flores \\
\hline
\end{tabular}

APS - Área produtora de sementes - PSC - Pomar de sementes clonal

Caracterização edafo-climática do local: a região possui precipitação pluviométrica média anual de $1.166 \mathrm{~mm}$, temperatura média de $21^{\circ} \mathrm{C}$ e o clima pela classificação de Köppen é classificado como sendo tropical de altitude - Cwa - temperado úmido com inverno seco e verão quente. $\mathrm{O}$ solo é do tipo latossolo vermelho distrófico típico e vermelho amarelo distrófico típico, com textura argilosa ou muito argilosa, bem estruturado. A topografia é plana (chapada) e a vegetação nativa é característica do bioma Cerrado.

Delineamento experimental e mensuração das árvores: o delineamento experimental utilizado no teste de progênies foi o de blocos casualizados, com 77 tratamentos (progênies), com seis repetições em parcelas lineares de seis plantas, no espaçamento de plantio de 2 x $3 \mathrm{~m}$. Foram efetuadas cinco mensurações das árvores - DAP do tronco com fita métrica, altura total das árvores com clinômetro Suunto PM-5 360 PC e sobrevivência das árvores -, no $13^{\circ}$ mês ( $1^{\circ}$ ano $), 21^{\circ}$ mês $\left(2^{\circ}\right.$ ano), $38^{\circ}$ mês ( $3^{\circ}$ ano $), 60^{\circ}$ mês ( $5^{\circ}$ ano $)$ e $82^{\circ}$ mês $\left(7^{\circ}\right.$ ano), este último correspondendo à idade usual de corte das árvores para a fabricação de carvão vegetal.

Determinação da densidade aparente do lenho/anéis de crescimento anuais: na determinação da densidade aparente do lenho dos anéis de crescimento anuais do tronco das árvores foram selecionadas, aos sete anos de idade, 26 progênies das 39 mais produtivas, decorrentes da seleção entre e dentro, para a formação de pomar de hibridação por enxertia. Nessas progênies foram amostrados os blocos 1, 3 e 5 (do total de seis) e, de cada bloco, foram selecionadas quatro árvores de melhor desenvolvimento, totalizando 312 árvores. Essas árvores foram cortadas e retiradas seções transversais do lenho na posição correspondente ao DAP dos seus troncos para a delimitação e determinação da densidade aparente do lenho dos anéis de crescimento anuais pela metodologia de densitometria de raios X - descrita por Tomazello Filho et al. (2008), Henriques (2012) e Arizapana-Almonacid (2013) -, no Laboratório de Anatomia e Densitometria de Raios X em Madeiras, do Departamento de Ciências Florestais da ESALQ/USP. Foram obtidos 624 perfis radiais da densidade aparente do lenho ( 26 progênies x 12 árvores $\mathrm{x} 2$ raios das amostras do lenho). Para a comprovação da anuidade dos anéis de crescimento foi identificada a data da formação e a respectiva localização da cicatriz resultante da aplicação da agulha do equipamento Pilodyn, na seção transversal do lenho tronco das árvores (novembro de 2008, árvores no $5^{\circ}$ ano) (Figura 1). 


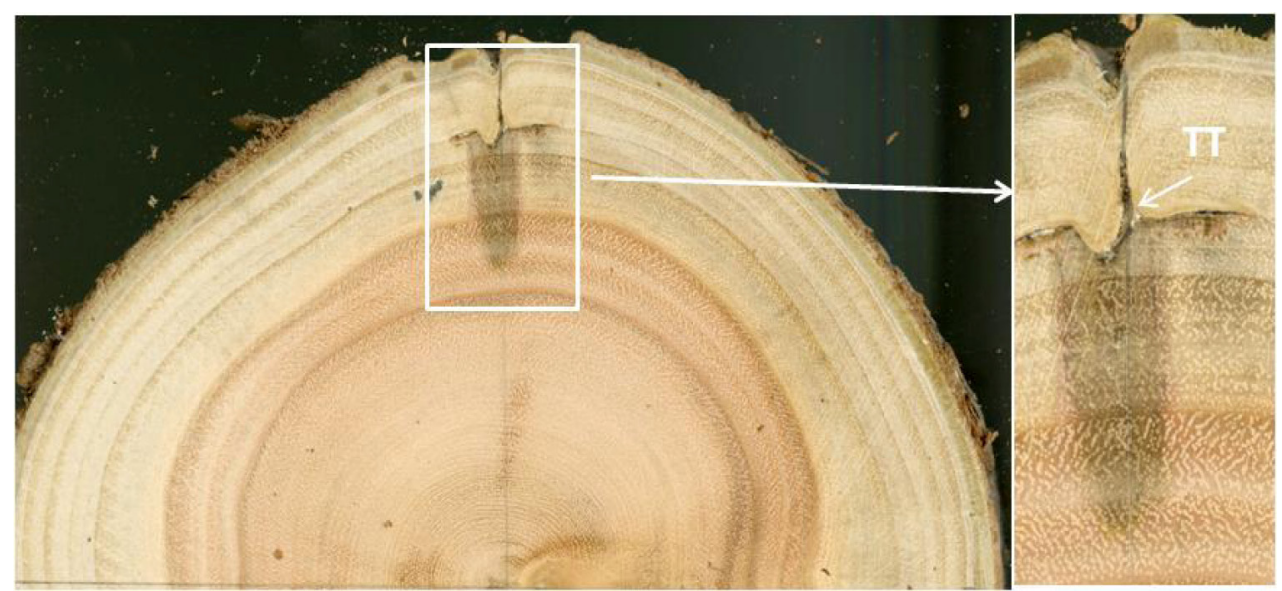

Figura 1. Seção transversal do lenho de Eucalyptus urophylla, evidenciando os anéis de crescimento e a cicatriz de novembro de 2008, induzida pela agulha do pilodyn e utilizada como referência para a determinação da anuidade dos anéis de crescimento. TT: Tecido Traumático.

Figure 1. Transversal section of Eucalyptus urophylla wood, evidencing the growth rings and the scar from November, 2008, induced by Pilodyn needle and used as a reference for determining the annual growth rings. Tा: Traumatic Tissue.

Análises e delineamento estatístico: a estimativa dos componentes de variância e dos parâmetros genéticos dos caracteres de crescimento e da densidade de lenho das árvores foi obtida pelo método de máxima verossimilhança restrita e melhor predição linear não viciada (REML/BLUP) empregando-se o software genético-estatístico SELEGEN-REML/BLUP (RESENDE, 2007). As análises foram realizadas considerando o delineamento em blocos casualizados, utilizando o modelo matemático:

$$
y=X r+Z a+W p+e
$$

sendo, y: vetor de dados; r: vetor dos efeitos de repetição (fixos), somados à média geral; a: vetor dos efeitos genéticos aditivos individuais (aleatórios); p: vetor dos efeitos de parcela (aleatórios); e: vetor de erros ou resíduos (aleatórios). As letras maiúsculas representam as matrizes de incidência para os referidos efeitos.

As variáveis quantitativas e os parâmetros genéticos das árvores de E. urophylla foram analisadas pelas equações descritas a seguir, admitindo-se que as progênies de polinização aberta como sendo formadas por indivíduos com grau de parentesco de meios-irmãos e sobrevivência completa.

Variância genética aditiva: $\hat{\sigma}_{a}^{2}=\left[\hat{a}^{1} A^{-1} \hat{a}+\hat{\sigma}_{\varepsilon}^{2} \operatorname{tr}\left(A^{-1} C^{22}\right)\right] / q$

Variância ambiental entre parcelas: $\hat{\sigma}_{c}^{2}=\left[\hat{c}^{\prime} \hat{c}+\hat{\sigma}_{\varepsilon}^{2} \operatorname{tr} C^{33}\right] / s_{1}$

Variância residual (ambiental + não aditiva):

$\hat{\sigma}_{\varepsilon}^{2}=\left[y^{\prime} y-\hat{r}^{\prime} X^{\prime} y-\hat{a}^{\prime} Z^{\prime} y-\hat{c}^{\prime} W^{\prime} y\right] /[N-r(x)]$

Variância fenotípica individual: $\hat{\sigma}_{f}^{2}=\hat{\sigma}_{a}^{2}+\hat{\sigma}_{c}^{2}+\hat{\sigma}_{\varepsilon_{2}}^{2}$

Herdabilidade individual no sentido restrito: $\hat{h}_{a}^{2}=\frac{\hat{\sigma}_{a}^{2}}{\hat{\sigma}_{f}^{2}}$

Coeficiente de determinação dos efeitos de parcela: $\hat{C}_{p}^{2}=\frac{\hat{\sigma}_{c}^{2}}{\hat{\sigma}_{f}^{2}}$

Herdabilidade da média de progênies: $\quad \hat{h}_{m}^{2}=\frac{\hat{f}(1 / 4) \cdot \hat{\sigma}_{a}^{2}}{(1 / 4) \cdot \hat{\sigma}_{a}^{2}+\frac{\hat{\sigma}_{c}^{2}}{r}+\frac{\left(0,75 \cdot \hat{\sigma}_{a}^{2}+\hat{\sigma}_{\varepsilon}^{2}\right)}{n \cdot r}}$
Acurácia da seleção de progênies: $r_{a a}=\sqrt{\hat{h}_{m}^{2}}$

Coeficiente de variação genética aditiva individual: $C V_{g i}(\%)=\frac{\sqrt{\hat{\sigma}_{a}^{2}}}{\hat{m}} .100$

Coeficiente de variação genotípica entre progênies: $C V_{g p}(\%)=\frac{\sqrt{0,25 \cdot \hat{\sigma}_{a}^{2}}}{\hat{m}} \cdot 100$

Coeficiente de variação experimental: $C V_{\varepsilon}(\%)=\frac{\sqrt{\left[\left(0,75 . \hat{\sigma}_{a}^{2}+\hat{\sigma}_{\varepsilon}^{2}\right) / n\right]+\hat{\sigma}_{c}^{2}}}{\hat{m}} \cdot 100$,

Coeficiente de variação relativa: $C V_{r}=\frac{C V_{g p}}{C V_{\varepsilon}}$ 
em que: $C^{22}, C^{33}, C^{44}$ e $C^{55}$ vêm da inversa de C. $C$ : matriz dos coeficientes das equações de modelo misto; tr: operador traço matricial; $\mathbf{r}(\mathbf{x})$ : posto da matriz $\mathrm{X} ; \mathrm{N}, \mathbf{q}$, s: números de dados, de exemplares e de parcelas: n: número de plantas por parcela.

\section{RESULTADOS E DISCUSSÃO}

Na Tabela 2 são apresentados os dados da estimativa dos parâmetros genéticos para os caracteres altura total (ALT), diâmetro à altura do peito (DAP), volume individual do tronco (VOL) e densidade aparente do lenho das árvores (DEN).

Tabela 2. Estimativa de parâmetros genéticos para altura total, DAP, volume e densidade aparente do lenho da árvore em teste de progênies de polinização aberta de Eucalyptus urophylla, aos 1, 2, 3, 5 e 7 anos de idade.

Table 2. Estimation of genetic parameters for total height, DBH, bole volume and apparent density of wood in open pollinated progeny tests of Eucalyptus urophylla, at 1, 2, 3, 5 and 7 years of age.

\begin{tabular}{|c|c|c|c|c|c|c|}
\hline \multirow{2}{*}{ Parâmetros } & \multirow{2}{*}{ Caracteres } & \multicolumn{5}{|c|}{ Idades (anos) } \\
\hline & & 1 & 2 & 3 & 5 & 7 \\
\hline \multirow{4}{*}{$\hat{h}_{a}^{2}$} & ALT & $0,29 \pm 0,06$ & $0,33 \pm 0,06$ & $0,51 \pm 0,08$ & $0,49 \pm 0,08$ & $0,43 \pm 0,07$ \\
\hline & DAP & $0,10 \pm 0,03$ & $0,17 \pm 0,04$ & $0,15 \pm 0,04$ & $0,19 \pm 0,05$ & $0,22 \pm 0,05$ \\
\hline & VOL & $0,13 \pm 0,04$ & $0,25 \pm 0,05$ & $0,25 \pm 0,05$ & $0,26 \pm 0,06$ & $0,27 \pm 0,06$ \\
\hline & DEN & $0,29 \pm 0,21$ & $0,53 \pm 0,28$ & $0,59 \pm 0,29$ & $0,70 \pm 0,32$ & $0,68 \pm 0,31$ \\
\hline \multirow{3}{*}{$\hat{h}_{q j}^{2}$} & ALT & 0,3426 & 0,3385 & 0,5214 & 0,5026 & 0,4365 \\
\hline & DAP & 0,1312 & 0,171 & 0,1588 & 0,1990 & 0,2211 \\
\hline & $\begin{array}{l}\text { VOL } \\
\text { DEN }\end{array}$ & 0,1789 & 0,2506 & 0,2495 & 0,2658 & 0,2747 \\
\hline \multirow{4}{*}{$\hat{C}_{p}^{2}$} & ALT & 0,1525 & 0,0111 & 0,0129 & 0,0187 & 0,0113 \\
\hline & DAP & 0,1879 & 0.0038 & 0,0026 & 0,0028 & 0,0030 \\
\hline & VOL & 0,2316 & 0,0041 & 0,0029 & 0,0030 & 0,0032 \\
\hline & DEN & $2,078 \times 10^{-1}$ & $6,25 \times 10^{-3}$ & $8,495 \times 10^{-3}$ & $1,256 \times 10^{-2}$ & $3,287 \times 10^{-2}$ \\
\hline \multirow{4}{*}{$\hat{h}_{m}^{2}$} & ALT & 0,6072 & 0,7561 & 0,832 & 0,8207 & 0,8038 \\
\hline & DAP & 0,3340 & 0,6110 & 0,5943 & 0,6494 & 0,6739 \\
\hline & VOL & 0,3679 & 0,7011 & 0,7016 & 0,7155 & 0,7223 \\
\hline & DEN & 0,6500 & 0,8000 & 0,8200 & 0,8500 & 0,8300 \\
\hline \multirow{4}{*}{$\hat{h}_{a d}^{2}$} & ALT & 0,2810 & 0,2773 & 0,4497 & 0,4311 & 0,3675 \\
\hline & DAP & 0,1018 & 0,1340 & 0,1240 & 0,1571 & 0,1755 \\
\hline & VOL & 0,1405 & 0,2005 & 0,1996 & 0,2136 & 0,2213 \\
\hline & DEN & 0,2103 & 0,4204 & 0,4911 & 0,6110 & 0,6009 \\
\hline \multirow{4}{*}{ râa } & ALT & 0,7792 & 0,8695 & 0,9121 & 0,9059 & 0,8965 \\
\hline & DAP & 0,5779 & 0,7817 & 0,7709 & 0,8059 & 0,8209 \\
\hline & VOL & 0,6066 & 0,8373 & 0,8376 & 0,8459 & 0,8499 \\
\hline & DEN & 0,8079 & 0,8968 & 0,9071 & 0,9209 & 0,9097 \\
\hline \multirow{4}{*}{$\mathrm{CV}_{\mathrm{gi}}(\%)$} & $\overline{A L T}$ & 9,23 & 7,8 & 9,76 & 7,72 & 8,41 \\
\hline & DAP & 6,16 & 6,09 & 7,46 & 8,2 & 9,22 \\
\hline & VOL & 18,52 & 18,37 & 21,77 & 22,49 & 25,42 \\
\hline & DEN & 4,08 & 5,26 & 5,46 & 5,81 & 5,61 \\
\hline \multirow{4}{*}{$\mathrm{CV}_{\mathrm{e}}(\%)$} & ALT & 9,09 & 5,42 & 5,38 & 4,42 & 5,09 \\
\hline & DAP & 10,66 & 5,95 & 7,55 & 7,38 & 7,85 \\
\hline & VOL & 29,74 & 14,69 & 17,39 & 17,38 & 19,31 \\
\hline & DEN & 13,68 & 12,86 & 12,88 & 12,23 & 11,79 \\
\hline \multirow{4}{*}{$\mathrm{CV}_{\mathrm{r}}$} & ALT & 0,51 & 0,72 & 0,91 & 0,87 & 0,83 \\
\hline & DAP & 0,28 & 0,51 & 0,49 & 0,55 & 0,59 \\
\hline & VOL & 0.31 & 0.62 & 0.63 & 0.65 & 0.66 \\
\hline & DEN & 0,15 & 0,21 & 0,21 & 0,24 & 0,24 \\
\hline \multirow{4}{*}{$\mathrm{CV}_{\mathrm{gp}}(\%)$} & $\mathrm{ALT}$ & 4,62 & 3,9 & 4,88 & 3,86 & 4,21 \\
\hline & DAP & 3,08 & 3,05 & 3,73 & 4,1 & 4,61 \\
\hline & VOL & 9,26 & 9,18 & 10,89 & 11,25 & 12,71 \\
\hline & DEN & 2,04 & 2,63 & 2,73 & 2,90 & 2,80 \\
\hline \multirow{4}{*}{$\hat{m}$} & $\operatorname{ALT}(\mathrm{m})$ & 5,35 & 9,74 & 15,87 & 20,1 & 22,18 \\
\hline & $\mathrm{DAP}(\mathrm{cm})$ & 4,83 & 7.69 & 11,00 & 12,84 & 14,44 \\
\hline & $\operatorname{VOL}\left(\mathrm{m}^{3}\right)$ & 0,0053 & 0,0237 & 0,0810 & 0,1384 & 0,1959 \\
\hline & DEN $\left(\mathrm{g} / \mathrm{cm}^{3}\right)$ & 0,5262 & 0,5576 & 0,5851 & 0,6037 & 0,6203 \\
\hline \multirow{4}{*}{ LRT } & ALT & $32,79^{* *}$ & $81,54^{* *}$ & $133,40^{* *}$ & $116,99^{* *}$ & $104,19^{* *}$ \\
\hline & DAP & $5,58^{*}$ & $41,16^{\star *}$ & $38,00^{* *}$ & $48,99^{* \star}$ & $56,73^{* *}$ \\
\hline & VOL & $7,23^{* *}$ & $67,55^{\star *}$ & $73,18^{* *}$ & $73,93^{\star *}$ & $75,74^{* *}$ \\
\hline & DEN & $1,88 \mathrm{~ns}$ & $6,87^{* *}$ & $7,30^{* *}$ & $8,71^{* *}$ & $7,42^{\star *}$ \\
\hline
\end{tabular}

$\hat{h}_{a}^{2}$ herdabilidade individual dos efeitos aditivos; $\hat{h}_{a j}^{2}$ herdabilidade ajustada; $\hat{C}_{p}^{2}$ coeficiente de $\hat{m}$ determinação dos efeitos de parcelas; $\hat{h}_{m}^{2}$ herdabilidade da média de progênies; $h_{a d}^{2}$ herdabilidade dentro de progênies; ${ }^{p}$ áa acurácia; $C V$ gi coeficiente de variação genética aditiva individual; $C V$ coeficiente de variação experimental; $C V_{r}$ coeficiente de variação relativa; $C V_{g p}$ (\%) coeficiente de variação genética entre progênies; média do caráter; LRT teste da razão de verossimilhança; ALT altura total d tronco; DAP diâmetro à altura do peito; VOL volume e DEN densidade aparente do lenho. 
A partir do terceiro ano de idade as herdabilidades individuais dos efeitos aditivos $\left(\hat{h}_{a}^{2}\right)$ foram da ordem de 0,50 para ALT, considerada como alta; 0,20 para DAP e 0,25 para VOL, consideradas como medianas e 0,68 para DEN, considerada como alta, conforme Resende (1995). Esses valores corroboram valores encontrados na literatura.

Este parâmetro reflete a proporção da variância aditiva no contexto da variação fenotípica, ou seja, a parte da variação genética que é transmitida aos descendentes. Daí a importância da magnitude da proporção aditiva da variância genética (PAULA et al., 1996).

Outrossim, verifica-se que as herdabilidades são crescentes com a idade. Esta tendência nos leva a inferir a existência de maior influência do ambiente sobre as características juvenis (BORGES et al.,1980; KALIL FILHO et al., 1982). À medida que as árvores se tornam adultas, o genótipo exerce maior influência na expressão do fenótipo (BORGES, et al., 1980).

Estes valores evidenciam ainda a possibilidade de seleção precoce para os caracteres estudados a partir do terceiro ano de idade, especialmente a ALT para crescimento e DEN para características tecnológicas da madeira.

A herdabilidade ajustada $\left(\hat{h}_{4 j}^{2}\right)$ indica a acurácia dos valores obtidos para a herdabilidade individual dos efeitos aditivos, no sentido restrito, demonstrando a eficiência deste cálculo no experimento. Neste caso, elas foram coincidentes ou muito próximas a partir do segundo ano. No primeiro ano, em razão dos coeficientes dos efeitos de parcelas serem maiores que 10\% (ALT 15,25\%, DAP $18,79 \%$, VOL 23,16\% e DEN 20,78\%), as duas herdabilidades não foram coincidentes.

O coeficiente de determinação dos efeitos de parcelas $\left(C_{p}^{2}\right)$ foram inferiores a $1 \%$ a partir do segundo ano de idade, indicando um ótimo controle ambiental entre as parcelas e um adequado delineamento experimental. Resende (2002) salienta que este parâmetro quantifica a variabilidade das parcelas dentro do bloco e um valor superior a $10 \%$ pode interferir na estimativa dos parâmetros genéticos. Neste caso, este percentual ocorreu somente no primeiro ano, conforme relatado anteriormente e afetou a coincidência dos valores da herdabilidade ajustada com a herdabilidade aditiva individual.

As progênies apresentaram altas herdabilidades das médias de progênies $\left(\hat{h}_{m}^{2}\right)$, superiores a 0,60 , para os parâmetros de crescimento e densidade do lenho a partir do segundo ano e medianas no primeiro ano, conforme classifica Resende (1995) como herdabilidades baixas, valores entre 0,01 e 0,15 , medianas entre 0,15 e 0,50 e altas superiores a 0,50. A magnitude de seu valor indica bom controle genético na expressão dos caracteres e evidencia elevado potencial de seleção dentro do referido teste de progênies, com perspectivas de se obter ganhos genéticos. Vencovsky et al. (1992) recomenda seleção baseada na herdabilidade média, por ser um "nível mais elevado de precisão do que a baseada em parcelas ou plantas" pelo fato de aquela diminuir a influência dos erros experimentais.

A elevada herdabilidade média da DEN, entre as progênies das árvores, corrobora com os resultados de Malan (1988) em E. grandis que, da mesma forma, constatou variação significativa da densidade do lenho entre as suas progênies.

As herdabilidades dentro de progênies ( $\hat{h}_{a d}^{2}$ ) para caracteres de produção (ALT, DAP, VOL) e DEN foram medianas, até 0,50, conforme classificação de Resende (1995). Isto se deve ao já adiantado estado de melhoramento do material do Pomar de Sementes Clonal 2000 (Tabela 1).

Em relação à acurácia $\left(r_{a a}\right)$ foram verificados valores altos conforme classifica Resende (2002), acima de 0,77 para todos os caracteres de crescimento e qualidade do lenho a partir do segundo ano de idade e acima de 0,57 para todos os sete anos de avaliação. Isto evidencia boa relação entre o valor genético verdadeiro e o predito conforme Novaes (2014) que, citando ainda (BELTRAME et al., 2012; MORAES et al., 2011; RESENDE; DUARTE, 2007) encontraram resultados semelhantes. Estes valores indicam acerto na seleção do caráter com ganhos de produtividade. Para DEN a acurácia variou de 0,80 a 0,92 e a DEN variou de 0,53 a 0,62 (g. $\left.\mathrm{cm}^{-3}\right)$ do primeiro ao sétimo anos de idade (Tabela 2), corroborando com trabalhos de diversos autores como Tomazello Filho (1985, 1987) e Trugilho (2009).

O coeficiente de variação genética aditiva individual ( $\left.C V_{g i}\right)$, que expressa a percentagem de variação genética aditiva existente dentro da progênie, foi da ordem de 6,0 a 9,7 para ALT e DAP e de 18,0 a 25,0 para VOL. Moraes et al. (2014) encontrou tendência semelhante para VOL trabalhando com clones de Eucalyptus. Para DEN os valores foram de 4,0\% a 5,8 \% indicando pouca variação dentro de progênies. 
Já o coeficiente de variação genética entre progênies $\left(C V_{g p}\right)$ foi ainda menor, da ordem de $3,05 \%$ a $4,88 \%$ para ALT e DAP e de $9,18 \%$ a $12,7 \%$ para DEN. Este coeficiente, conforme menciona Sturion (1993), expressa em percentagem da média geral a quantidade de variação genética existente entre progênies. O nível desta magnitude pode ser explicado pelo fato de se tratar de progênies originadas de árvores matrizes selecionadas em diferentes estágios de melhoramento (Tabela 1). Estes valores indicam maiores possibilidades de acerto em seleção dentro de progênies, especialmente pelo caráter VOL, que entre progênies.

O coeficiente de variação experimental $\left(C V_{\varepsilon}\right)$ foi inferior a $10 \%$ para ALT e DAP das árvores para todas as idades, exceção apenas para o DAP no primeiro ano $(10,66 \%)$, considerado baixo, conforme Gomes (1990). O $C V_{\varepsilon}$ foi da ordem de 14,69\% a 19,31\% para ALT a partir do segundo ano considerado como médios conforme Gomes (1990).

Para DEN os valores do $\left(C V_{\varepsilon}\right)$ foram da ordem de 13,68\% no primeiro ano e de $11,79 \%$ aos sete, decrescendo com a idade, considerado como médios por Gomes (1990).

Este coeficiente fornece uma ideia, conforme Gomes (1990), da precisão do experimento e indica que o delineamento experimental adotado foi eficiente no controle da variação ambiental (SENNA et al., 2012).

Estes resultados estão em concordância com os resultados comumente relatados na literatura científica para eucalipto, entre eles Paula et al. (1996).

O Coeficiente de variação relativa $\left(C V_{r}\right)$ é uma relação entre o $C V_{g p}$ (variação genética) e $C V_{\varepsilon}$ (variação ambiental). Neste caso, verifica-se que a variação ambiental foi maior que a genética, cujos valores para todos os caracteres em todas as idades foram inferiores a um, o que evidencia perspectivas pouco favoráveis para ganhos genéticos na seleção entre progênies. $\mathrm{O} C V_{g i}$ já mostrou isto, indicando a seleção dentro de progênies.

Contudo Paula et al. (1996), relatou (ELDRIDGE, 1971) que afirmou que, em existindo variação estatisticamente significativa entre progênies, pode-se entender como possibilidade de melhoramento pela seleção. Também Paula et al. (1996), citando (DUDLEY; MOLL, 1969) que afirmaram que tendo em vista que a significância estatística não fornece a magnitude da variabilidade genética dentro da população, neste caso recorre-se a estimativa da herdabilidade no sentido restrito $\left(\hat{h}_{a}^{2}\right)$ (Tabela 2) que proporciona o conhecimento sobre a magnitude das variações genéticas e ambiental.

As médias dos crescimentos de todos os caracteres do primeiro ao sétimo anos foi de: ALT de

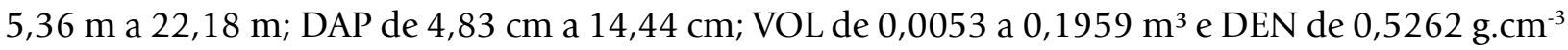
a $0,6203 \mathrm{~g} . \mathrm{cm}^{-3}$, respectivamente.

O incremento médio anual (IMA), medida comumente empregada para expressar produtividade de madeira, foi de $41 \mathrm{~m}^{3} \cdot \mathrm{ha}^{-1}$. ano ${ }^{-1}$ aos sete anos de idade, para a média das 77 progênies deste teste. Este cálculo foi feito usando-se a seguinte fórmula:

$41 \mathrm{~m}^{3} \cdot \mathrm{ha}^{-1}$. ano $^{-1}=\left\{\left[0,1959 \mathrm{~m}^{3}\right.\right.$ (volume de madeira médio das árvores) $x 1.666\left(\mathrm{n}^{\circ}\right.$ de árvores por ha) x 0,88 (média de sobrevivência das árvores no experimento)] / 7 (idade em anos)\}.

Nota: o cálculo do VOL já levou em conta o valor 0,5 para fator de forma das árvores.

A estimativa dos parâmetros genéticos para crescimento e densidade aparente do lenho de árvores de E. urophylla em teste de progênies de meios irmãos (Tabela 1), mostrou que a população tem $C V_{g p}$ na faixa de $5 \%$ a $10 \%$ para todos os caracteres para todas as idades, valor considerado baixo conforme Resende (1992).

Individualmente, $C V_{g i}$ possui valores duas vezes maiores, porém baixos conforme Resende (1992), indicando melhores ganhos na seleção dentro de progênies.

Este teste de progênies é oriundo de um Pomar de Sementes Clonal, fruto de vários estágios de melhoramento de suas árvores matrizes (Tabela 1), sugerindo que em vista disto os coeficientes de variação genéticos sejam baixos.

Ocorre que a população tem $\hat{h}_{m}^{2}$ de magnitude alta $(0,60)$ e $r_{\text {áa }}$ também alta $(0,77)$, conforme Resende (1992). A herdabilidade das médias de progênies éo parâmetro recomendado por Vencovsky (1992) como preferencial para seleção, tendo em vista que ele reduz o efeito do ambiente.

Embora a base genética seja de baixa magnitude, o teste da razão de verossimilhança (LRT) indica diferenças estatisticamente significativas $(\mathrm{p}<0,01)$ para todos os caracteres em todas as idades, exceção somente para DAP no primeiro ano $(\mathrm{p}<0,05)$ e DEN também no primeiro ano (ns), não 
significativo. As diferenças significativas detectadas indicam variação genética entre progênies e potencial de aplicação no melhoramento genético por meio da seleção das árvores das progênies com melhor desempenho para os parâmetros analisados.

\section{CONCLUSÕES}

Os resultados do presente trabalho permitem concluir que, (i) existem variações genéticas entre as progênies para os caracteres de crescimento e da qualidade do lenho; (ii) os valores de herdabilidade média das progênies $\left(\hat{h}_{m}^{2}\right)$ para os caracteres avaliados são altos, acima de $83 \%$ para altura, $67 \%$ para DAP, $72 \%$ para volume e de $80 \%$ para densidade aparente do lenho e permitem efetuar a seleção pretendida das melhores progênies; (iii) a seleção precoce é eficiente quando aplicada para as árvores no $3^{\circ}$ ano para os caracteres de produção e no $2^{\circ}$ ano para a densidade aparente do lenho e (iv) os anéis de crescimento são formados anualmente, constituindo-se em eficiente ferramenta para a determinação dos incrementos anuais do diâmetro do tronco, da densidade do lenho - pela densitometria de raios X - e de outros parâmetros do crescimento das árvores.

\section{REFERÊNCIAS BIBLIOGRÁFICAS}

ARIZAPANA-ALMONACID, M. A. Avaliação do crescimento e da qualidade do lenho de árvores de Eucalyptus urophylla S.T. Blake, de 8 anos, de teste de progênie visando a produção de carvão. 2013. 161 p. Dissertação (Mestrado em Recursos Florestais) - Escola Superior de Agricultura "Luiz de Queiroz",Universidade de São Paulo, Piracicaba, 2013.

BELTRAME, R.; BISOGNIN, D. A.; MATTOS, B. D.; CARGNELUTTI, FILHO, A.; HASELEIN, C. R.; GATTO, D. A.; SANTOS, G. A. Desempenho silvicultural e seleção precoce de clones de híbridos de eucalipto. Pesquisa Agropecuária Brasileira, Brasília, v. 47, n. 6, p. 791-796, 2012.

BORGES, R. C. G.; BRUNE, A.; SILVA, J. C. ; REGAZZI, A. J. Estimativa de parâmetros genéticos em Eucalyptus grandis W. Hill ex Maiden. Revista Árvore, Viçosa, v. 4. n. 2, p.134-145, 1980.

BROOKHOUSE, M. Eucalypt dendrochronology: past, present and potential. Australian Journal of Botany, Canberra, v. 54, p. 435-449, 2006.

DUDLEY, J. M. ; MOLL, R. H. Interpretation and use of estimates of heritability and genetic variances in plant breeding. Crop Science, Madison, v. 9, n. 3, p. 257-262, 1969.

ELDRIDGE, K. G. Genetically improved Eucalyptus seed for Australian Pulpwood Forest. Appita, Victoria, v, 24, n. 2, p. 105-109, 1971.

FONSECA, A. G.; BARBOSA, M.; LOBATO, R. C. Ensaios de proccedências de Eucalyptus urophylla S.T.BLAKE. In: CONGRESSO FLORESTAL BRASILEIRO, 5., Olinda, 1986. Anais... São Paulo: SBS, 1986. p.14-17.

GRATTAPAGLIA, D. Aplicações operacionais de marcadores moleculares. In: BORÉM, A. (Ed.). Biotecnologia florestal. Viçosa: Suprema, 2007. p. 175-200.

GOMES, F. P. Curso de estatística experimental. 13 ed. Piracicaba: Nobel, 1990. 467 p.

HENRIQUES, E.P. Variabilidade genética em progênies de Eucalyptus urophylla S.T. Blake para a produção de carvão. 2012. 75 p. Dissertação (Mestrado Ciência Florestal) - Universidade Estadual "Júlio de Mesquita Filho", Botucatu. 2012.

KALIL FILHO, A. N.; PIRES, C. L. S.; GURFINKEL, J. Estimação de parâmetros genéticos e observação do comportamento em Eucalyptus saligna Smith em Angatuba (SP). In: CONGRESSO ANUAL DA ABCP SEMANA DO PAPEL, 11, 1982, São Paulo. Anais... São Paulo: ABTCP, 1982. 
KNAPIC, S.; PIRRALHO, M.; LOUZADA, J.L.; PEREIRA, H. Early assessment of density features for 19 Eucalyptus species using X-ray microdensitometry in a perspective of potential biomass production. Wood Science and Technology, New York, v. 48, p.37-49. 2014.

MALAN, F. S. Genetic variation in some growth and wood properties among 18 full-sib families of South African grown Eucalyptus grandis: a preliminary investigation. South African Forestry Journal, Pretoria, n. 146, p.38-43, 1988.

MORAES, C. B.; FREITAS, T.C.M.; PIERONI, G.B.; RESENDE, M.D.V.; ZIMBACK, L.; MORI, E.S. Estimativa de parâmetros genéticos para seleção precoce de clones de Eucalyptus para região com ocorrência de geadas. Scientia Forestalis, Piracicaba, v. 42, n. 102, p. 219-227, 2014.

MORAES, C. B.; DE PIERI, C.; FRAGOSO, A. M.; GRANDE, J.; UESUGI, G.; MARTINS, M. R. S. G.; CARIGNATO, A.; RODRIGUES, D. P.; ZIMBACK, L.; MOREIRA, R. M.; MORI, E. S. Genetic variability in Eucalyptus clone for rust Puccinia psidii resistance. In: IUFRO WORKING GROUP IMPROVEMENT AND OF CULTURE EUCALYPTUS. 2011, Porto Seguro. Proceedings...Porto Seguro: IUFRO, 2011.

PAULA, R. C.; BORGES, R. C. G.; PIRES, I. E.; BARROS, N. F.; CRUZ, C. D. Estimativa de parâmetros genéticos em famílias de meios-irmãos de Eucalyptus camaldulensis DEHNH. I. Características de crescimento e densidade básica da madeira. Revista Árvore, Viçosa, v. 20. n. 3, p.309-317, 1996.

PRYOR, L. D.; JOHNSON, L. A. S. A classification of the Eucalyptus. Canberra: Australian National University, 1971. $101 \mathrm{p}$.

RESENDE, M. D. V.; DUARTE, J. B. Precisão e controle de qualidade em experimentos de avaliação de cultivares. Pesquisa Agropecuária Tropical, Goiânia. v. 37, n. 3, p. 182-194, 2007.

RESENDE, M. D. V. Genética biométrica e estatística no melhoramento de plantas perenes. Colombo: Embrapa Florestas, 2002, 975 p.

RESENDE, M. D. V. Delineamento de experimentos de seleção para maximização da acurácia seletiva e do progresso genético. Revista Árvore, Viçosa, v. 19, n. 4, p. 479-500, 1995.

RESENDE, M. D. V. SELEGEN-REML/BLUP: sistema estatístico e seleção genética computadorizada via modelos lineares mistos. Colombo: Embrapa Florestas, 2007.

ROCHA, M. G. B.; PIRES, I. E.; XAVIER, A.; CRUZ, R. R.; ROCHA, R. B. Avaliação genética de progênies de meios-irmãos de Eucalyptus urophylla, utilizando os procedimentos REML/BLUP e E(QM). Ciência Florestal, Santa Maria, v.16, n. 14, p. 369-379, 2006.

SENNA, S. N.; FREITAS, M. L. M.; ZANATTO, A. C. S.; MOAIS, E.; ZANATA, M.; MORAES, M. L. T.; SEBBENN, A. M. Variação e parâmetros genéticos em teste de progênies de polinização livre de Peltophorum dubium (Sprengel) taubert em Luiz Antônio-SP. Scientia Forestalis, Piracicaba, v. 40, n. 95, p. 345-352, 2012.

STURION, J. A. Variação genética de características de crescimento e de qualidade da madeira em progênies de Eucalyptus viminalis LABILL. 1993. 112 p. Tese (Doutorado em Ciência Florestal). Universidade Federal do Paraná, Curitiba. 1993.

TITON, M.; XAVIER. A.; OTONI, W. C.; REIS, G. G. Efeito do AIB no enraizamento de miniestacas e microestacas de clones de Eucalyptyus grandis W. Hill ex Maiden. Revista Árvore, Viçosa, v. 27, n. 1. p. 1-7, 2003.

TOMAZELLO FILHO, M. Variação radial da densidade básica e da estrutura anatômica da madeira de Eucalyptus globulus, E. pellita e E. acmenioides. IPEF, Piracicaba, n. 36, p. 35-42, 1987. 
Mauri et al. - Morfologia das fibras do lenho de clones de

Eucalyptus urophylla $\mathrm{x}$ Eucalyptus grandis em diferentes topografias e altitudes

TOMAZELLO FILHO, M. Variação radial da densidade básica e da estrutura anatômica da madeira de Eucalyptus saligna e E. grandis. IPEF, Piracicaba, n. 29, p. 37-45, 1985.

TOMAZELLO FILHO, M.; BRAZOLIN, S.; CHAGAS, M.P.; OLIVEIRA, J.T.S.; BALLARIN, A.W.; BENJAMIN, C.A. Application of X-ray tecnhique in non-destructive evaluation of eucalypt wood. Maderas. Ciencia $y$ Tecnología, Concepción, v.10, p.139-149, 2008.

TRUGILHO, P. Densidade básica e estimativa da massa seca e lignina na madeira de espécies de Eucalyptus. Ciência Agrotecnologia, Lavras, v.33, n.5, p.1228-1239, 2009.

Recebido em 21/03/2016

Aceito para publicação em 20/07/2016 